\title{
Patología dental y dieta de la población de Yuthu (400 - 100 a. C) en el Periodo Formativo del Cusco, Perú
}

\section{Dental pathology and diet of the population of Yuthu (400 - $100 \mathrm{BC})$ in the Formative Period of Cusco, Peru}

\author{
Angela Silvia Ricalde Pino \\ https://orcid.org/0000-0002-4631-2793 \\ Universidad Nacional San Antonio Abad del Cusco \\ silviaricaldeg@gmail.com
}

\section{RESUMEN}

En un contexto funerario, los restos humanos que mejor estado de conservación presentan al paso del tiempo y de los que más información se puede obtener relacionado al modo de vida, procesos patológicos, hábitos alimenticios, perfiles de salud bucal, inmunidad y prácticas culturales, de un individuo, son los restos óseos y las piezas dentales. El presente análisis interdisciplinario realizado en 17 individuos, procedentes de las excavaciones realizadas en el sitio arqueológico de Yuthu, revela el precario perfil de salud bucodental y paleopatologías dentales que afectaban a estos individuos. Llegando a identificar, para esta región del Perú, los primeros reportes y evolución de paleopatologías dentales que hasta la actualidad vienen afectando a la humanidad.

Palabras clave: bioarquelogía, paleopatología dental, salud bucal, hábitos alimenticios. 


\section{ABSTRACT}

In a Funerary context, the human remains that have better state of conservation over time and from which most information can be obtained related to the lifestyle, pathological processes, feeding habits, oral health profiles, inmunity and cultural practices, of an individual, are the bones and teeth. The present interdisciplinary analysis, reveals the precarious oral health and paleopathology that affected these individuals, which allowed to identify, for this región of Peru, the first reports and evolution of dental paleopathology that until now have been affecting humanity.

Keywords: bioarchaeology; dental paleopathology; oral health; feeding habits.

Recibido: 20/09/2021 - AcePtado: 08/10/2021 - Publicado: 25/11/2021

\section{INTRODUCCIÓN}

La importancia del estudio de las piezas dentales radica en la gran cantidad de información que poseen estos tejidos de los que, por medio de los correctos análisis, podemos obtener datos sobre: Dieta, prácticas culturales, nutrición, paleopatologias, perfiles de salud, inmunidad, que un individuo y en escala de una población pueden presentar a lo largo de su vida. Los estudios Bioarqueológicos relacionados a la salud bucodental y al análisis detallado de paleopatologías dentales llevados a cabo a nivel internacional son amplias (Larsen, 2003; Hillson, 1996; Kutsner, 2003; Rodríguez, 2005, Previgliano, Ceruti, Arias, Gonzales y Reinhard, 2005; Indriati, 1998; Indriati y Buikstra, 2001), a nivel nacional (Valdivia, 1988; Tomasto, 2009; Pezo, 2010; Bethard, Gaither,Vásquez, Rosales y Kent, 2008; Van Dalen, 2015; Verano, 1997; Altamirano, 2013), mientras que para la Región del CusCo, las investigaciones son escasas y superficiales en el tema (Torres, 2003; Bonnet, 2001; Davis, 2011).

La presente investigación interdisciplinaria, entre las disciplinas de la Arqueología y la Odontología, tiene el objetivo de identificar las frecuencias y los factores que influenciaron en la presencia de paleopatologías dentales presentes en la población de Yuthu, El análisis presentado aquí pretende contribuir las escasas investigaciones sobre paleopatologías dentales en la Región del Cusco, cuyo aporte resulta relevante para conocer los modos de vida y los perfiles de salud bucodental de esta población perteneciente al Periodo Formativo del Cusco.

Yuthu, se encuentra a una altitud de 3590 m s.n.m, en las faldas del cerro Yuthu a orillas de la laguna de Huaypo. Extendida a lo largo de una pampa altiplánica con elevaciones geográficas que oscilan entre 3200 a 4000 m.s.n.m. La zona geográfica es adecuada para la siembra de cereales nativos, como Quinua y Kiwicha, y tubérculos como, papa y oca; así como para el pastoreo de camélidos (Davis y Delgado, 2009). 


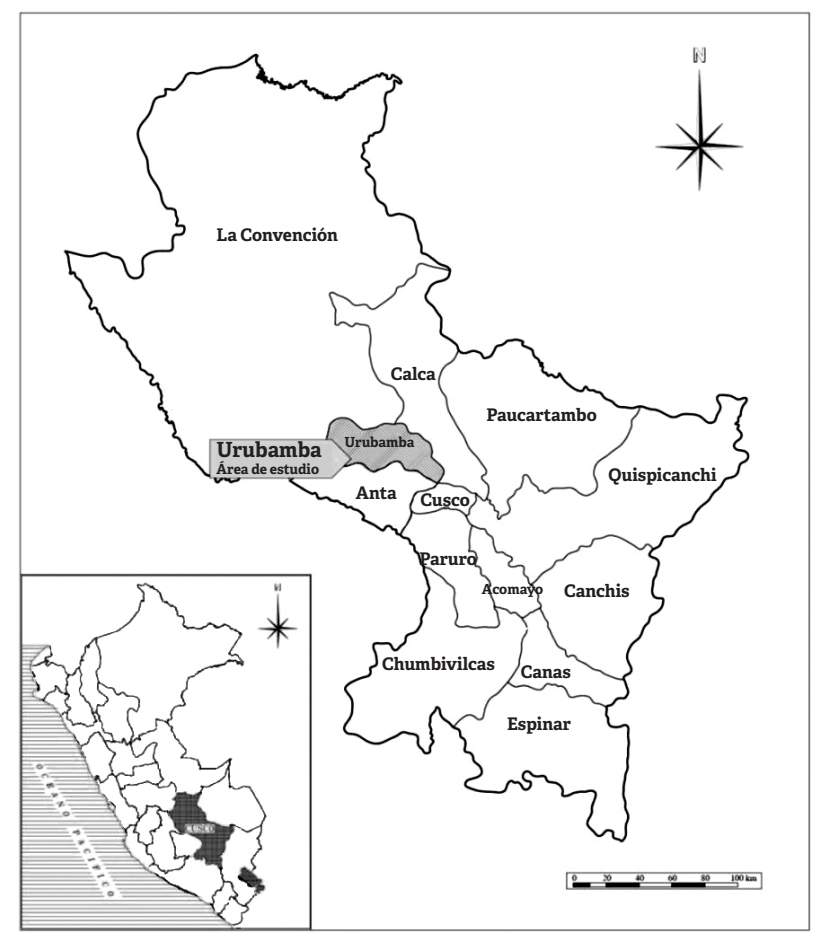

Figura 1. Mapa de la ubicación del sitio arqueológico de Yuthu.

El sitio Arqueológico de Yuthu fue identificado por primera vez en el año 2004, como parte del Proyecto de Reconocimiento Intensivo de la pampa de Xaquixaguana llevada a cabo por Alan Covey, entre las provincias actuales de Anta, Chinchero y Maras (Covey y Yepez Valdez, 2004).

Posteriormente, entre los años 2005 al 2009, se realizaron Investigaciones Arqueológicas con excavaciones llevadas a cabo por los Arqueólogos Carlos Delgado y Allison Davis, dando importancia al sitio de Yuthu por la presencia de cerámica Chanapata o Chanapata derivado, característico de las ocupaciones tardías del Periodo Formativo, lo que aseguraba que no existió ocupaciones tardías y/ o disturbaciones, por lo que resulta un espacio relevante para lograr entender el desarrollo social del Período Formativo (Davis y delgado, 2009).

De acuerdo con las conclusiones obtenidas de las excavaciones, estudios arqueológicos, y de los fechados radiocarbónicos realizados, esta población tuvo una ocupación entre 400 - 100 a. C., Periodo Formativo Tardío. Los pobladores de Yuthu fueron pastores de llamas y alpacas de acuerdo a los análisis de restos óseos de fauna el $68.26 \%$ son huesos de camélido. En lo referente a la agricultura, los análisis de restos carbonizados de plantas, demostraron un mayor porcentaje de cultivo de quinua (Chenopodium quinoa) con un 73.18\%, seguido maíz (Zea Mays)con 9.7\%. Estuvieron 


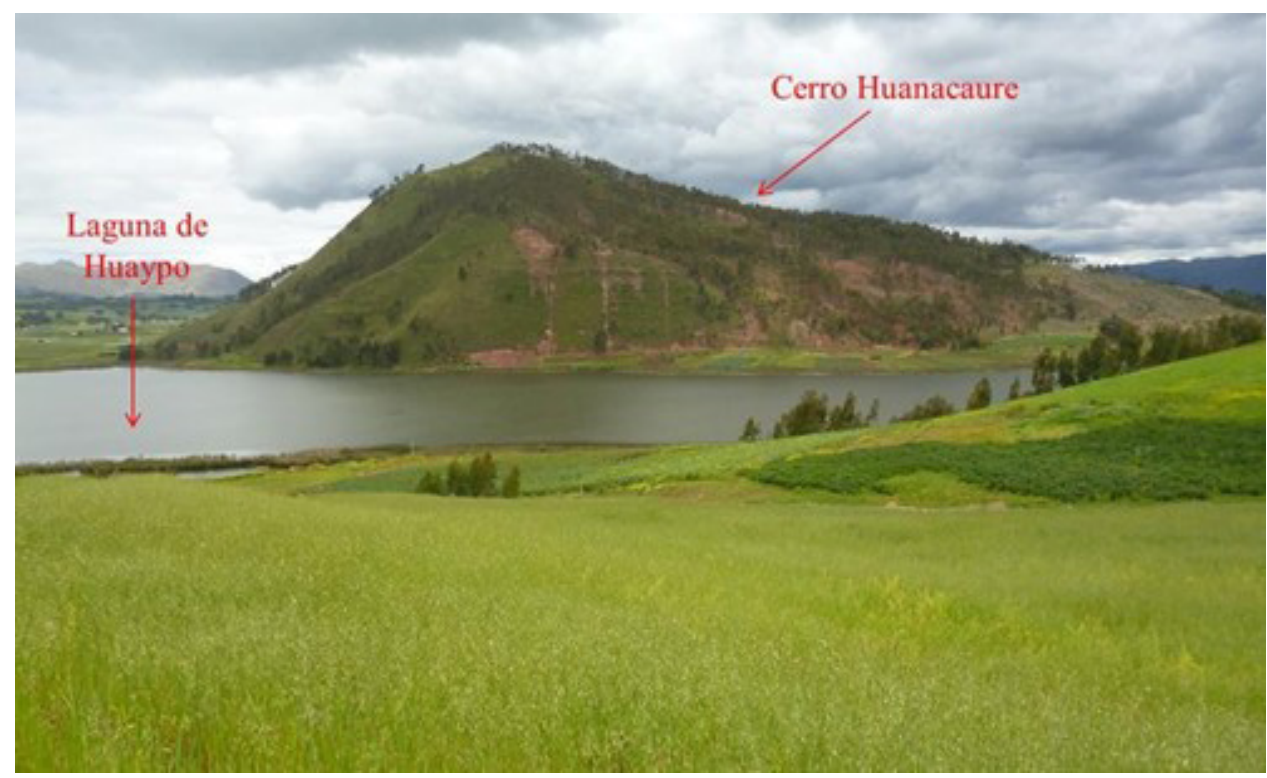

Figura 2. Vista del sitio arqueológico de Yuthu se ubica a orillas de la Laguna de Huaypo.

ubicados estratégicamente dentro un sistema político regional, partícipes de redes de intercambio que incluyeron zonas de selva y sierra, realizaron divisiones de espacios, doméstico y ceremonial (Davis y Delgado, 2009).

\section{ASPECTOS GENERALES DE YUTHU}

En base a las excavaciones realizadas en Yuthu, entre los años 2005 y 2009, se presentan los siguientes materiales recuperados: En lo referente a cerámica, esta se encontró muy fragmentada, perteneciente al estilo Chanapata derivado, por la mayor presencia del subtipo Chanapata Rojo.

Respecto al material lítico, se hallaron: piedras para molienda, manos de moler y batanes, en su mayoría hechos de cantos rodados de río, también se hallaron hachas, cuencos tallados, cuentas figurinas, raspadores, taladros, artefactos realizados en obsidiana, sin fuente conocida en Cusco, provenientes de fuentes cercanas como Chivay o Alca en Arequipa o Quispisisa en Ayacucho, con este material realizaron herramientas utilitarias de formas unifaciales y bifaciales, puntas de proyectil.

Por otra parte, se registraron implementos utilitarios: huesos trabajados como Ruk'is para labores de tejido, espátulas, alfileres para unir telas, t'ípinas, perforadores, cuentas todas hechas en material óseo proveniente de camélidos. Asimismo, se halló un diente de Guacamayo (Ara sp.) ave proveniente de la selva de Cusco o Puno, constituyendo una evidencia de redes de intercambio hacia las zonas de la Selva. 
En cuanto a la arquitectura, en Yuthu actualmente no se observan construcciones sobre la superficie del terreno, en las excavaciones, realizadas por Davis y Delgado en el año 2009, demostraron que los individuos de Yuthu poseían una división entre los espacios ceremonial y doméstico dentro de su comunidad. El sitio de Yuthu se identificaron dos sectores: Sector Sur, Ceremonial, con la Unidad A de mayor extensión y Sector norte, Doméstico, con la unidad D de mayor extensión, diferenciadas por sus formas arquitectónicas y técnicas constructivas. Durante la fase inicial, dentro del Sector Doméstico, presentó viviendas simples, que consistían en hoyos cavados en el suelo geológico, los que en algunos casos presentaban techumbres simples de paja, ubicadas en las laderas naturales del cerro.

Por otro lado, el Sector Ceremonial, presenta una ligera modificación de la pendiente del cerro para realizar una plataforma, sobre la que se erigió una estructura semisubterránea conformada por un muro de contención, banquetas anchas y mampostería formal, elaboradas con piedras y mortero de barro.

Las diferencias de actividades realizadas en ambos sectores marcan la diferencia. Mientras que en el sector doméstico se presentan fogones, cerámica llana de formas restringidas como jarras, ollas, principalmente utilizadas para guardar y preparar alimentos, almacenes y restos alimenticios, dando a entender que en este sector se realizaba almacenamiento, preparación y desecho de comidas, en el Sector Ceremonial se presenta mayor presencia de los subestilos de cerámica pintada y de vasijas de formas abiertas como platos, cuencos, formas que se utilizan para servir. De acuerdo a dichas características se percibe el contraste funcional en cada sector, ambos sectores ocupados durante el mismo tiempo El Sector Ceremonial con un Fechado de 417 - 62 a. C. y el Sector Doméstico con un fechado de 403 - 96 a. C. (Davis y delgado, 2009).

Posteriormente, durante la fase de ocupación final se presentaron similares alineamientos y amontonamiento de piedras asociados a entierros humanos en ambos sectores, dejando de lado la diferenciación de espacios, y constituyendo un cementerio (Davis y delgado, 2009).

En lo referente al análisis de restos carbonizados de plantas y el análisis de restos óseos hallados durante las excavaciones, realizados en base a el análisis de restos óseos de fauna y restos carbonizados de plantas, se obtuvieron los siguientes resultados:

Los análisis de restos óseos de fauna fueron: Presencia de Llamas y Alpacas (Lama Glama y Lama Pacos, 68.25\%), Cuy doméstico (Cavia porcellus, 5,23\%), pato silvestre (Anas sp.,0,49\%), galletera (Fulica sp., 0,31\%), búho terrestre (Athene cunicularia 0,11\%), garza (Aredeidae, 0,02\%), aguilucho (Buteo sp.0,04\%), águila (Geranoetus, $0,31 \%$ ), venado de cola blanca (Odocoileus virginianus, $0,98 \%$ ). En lo referente a restos 
carbonizados de plantas cultivadas, el mayor porcentaje presente fue la Quinua 73, 18\%, maíz(9,7\%), frijol (Phaseolus vulgaris, 0,12\%), presencia de semillas de Solanum $S p,(0.08 \%)$ género de plantas silvestres, pero entre ellas algunas especies de papa, presencia de semillas de Oxalis sp.(0,31\%), que son plantas silvestres, entre ellas oca domesticadas (Oxalis tuberosa), Del mismo modo, se halló semillas de Amaranthus (2,15\%), género de especies silvestres y algunas cultivadas como la Kiwicha (Amaranthus caudatus) (Vázquez y Rosales, 2009).

\section{CONTEXTOS FUNERARIOS}

Los contextos funerarios hallados fueron 23 , en los que se evidenciaron dos tipos, los más tempranos corresponden a contextos funerarios compuestos por una matriz cavada en el suelo geológico, el individuo en posición flexionada; el segundo tipo de contextos funerarios fueron entierros como parte del relleno de construcción no presentaban matriz los individuos se encontraban en posición flexionada, constituyendo esta característica hasta el final de la ocupación en ambos sectores. Dichos contextos funerarios estuvieron asociados a alineamientos o amontonamientos de piedras posiblemente parte de alguna practica funeraria (Davis y delgado, 2009; Ricalde y Nuñez, 2017).

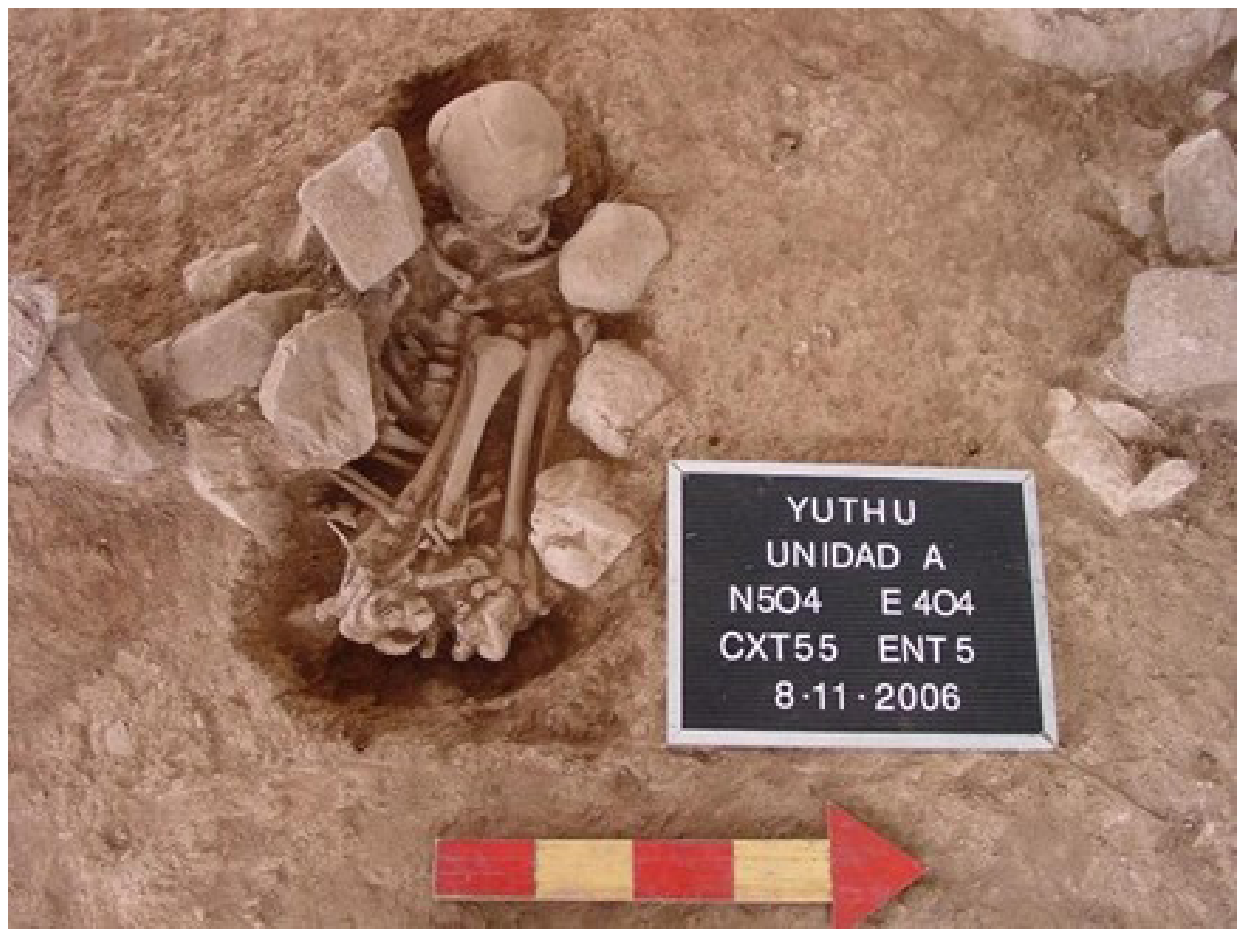

Figura 3. Contexto Funerario, Unidad A, individuo en posición flexionada, matriz cavada en el suelo geológico, asociado a alineamiento de piedras. 
Los individuos presentaban deformación craneana de tipo tabular oblicua, asimismo se evidenció la presencia de ritos funerarios que incluían grados y tipos de quemado en los cuerpos de los individuos y otros materiales.

La presencia de traumas en el esqueleto demostró que tanto hombres, mujeres y niños fueron víctimas de violencia interpersonal (Andrushko, 2008). Esto indica que el transcurso del período Formativo no fue pacífico, aunque no hay suficiente evidencia para determinar la causa de tales conflictos sociales en Yuthu (Davis, 2011).

\section{PALEOPATOLOGÍA}

El término paleopatología deriva de dos vocablos griegos: paleo que significa antiguo y pathos que quiere decir patología. Investiga el desarrollo de las enfermedades (Brier, 1944). Es una ciencia cuyo interés es tratar de arribar a un amplio entendimiento de la vida, costumbres y enfermedades de las civilizaciones pasadas correlacionándolas en el contexto cultural e histórico (Aufderheide, 2000). Por consiguiente, la paleopatología dental se define como el estudio de las estructuras, funciones y enfermedades del aparato o sistema estomatognático, a partir de restos óseos humanos procedentes de tiempos antiguos. El esqueleto dentomaxilofacial posee una gran importancia dado que son los restos que mejor se conservan, la información que se puede obtener del análisis de los restos humanos de un individuo en concreto, son la identificación del sexo, edad; la existencia de ciertos hábitos (alimenticios, culturales); las manifestaciones de procesos patológicos y alteraciones diversas (Kutsner, 2003)

\section{INDICADORES DE SALUD ORAL UTILIZADOS EN LA PRESENTE INVESTI- GACIÓN Y SUS BREVES ETIOLOGÍAS}

\subsection{Caries dental}

La caries dental es una enfermedad cuya etiología es de carácter multifactorial, implica una interacción entre los dientes, la saliva y la microflora oral como factores del huésped y la dieta (frecuencia en el consumo de carbohidratos) como factor externo.

Se trata de una forma singular de infección en la que se acumulan cepas específicas sobre la superficie del esmalte dental, donde elaboran productos ácidos y proteolíticos que desmineralizan la superficie y digieren su matriz orgánica (Sapp, Eversole \& Wysocki, 1998, p. 62). Si no se llega a controlar la infección, la disolución ácida provocada por las bacterias llegará a formar una cavidad que logrará extenderse hasta la cavidad pulpar, la misma que contiene una gran cantidad terminaciones nerviosas y vasos sanguíneos (Mejía, Lomeli y Gaxiola, 2012). 
En poblaciones prehispánicas, existió caries en menor porcentaje que en la actualidad, a medida que los pueblos se iban civilizando y llegan a incorporar carbohidratos refinados a su dieta, aumentó el porcentaje de caries (Valdivia,1988).

Valdivia (1988) sostiene que el poblador del ande consume alimentos duros y semi crudos como el charqui, la quinua, la cancha, etc. Estos alimentos de

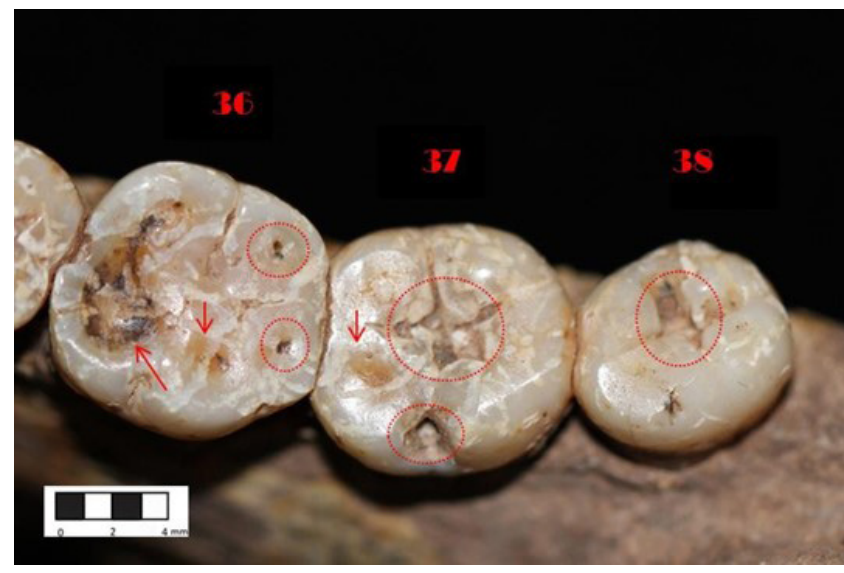

Figura 4. Individuo 3, muestra las superficies oclusales y vestibular, con presencia de caries de esmalte. textura abrasiva ayudaban a una limpieza natural de los dientes durante la masticación, evitando así en cierta medida, la acumulación de restos de alimentos en la superficie de las piezas dentales.

Otros autores sostienen que las culturas menos desarrolladas, como en el Periodo Arcaico, presentan menos casos de caries, mientras que las culturas con mayor desarrollo como la Inca con una economía agrícola y de intenso intercambio con las zonas de litoral y la selva son más susceptibles a la caries (Valdivia, 1988; Bonnet, 2001; Tomasto, 2009).

\subsection{Cálculo dental}

Cálculo dental se considera a todo depósito calcificado que se encuentra adherido a la superficie dental o a otras estructuras solidas en la cavidad oral. Aparece por calcificación de la placa bacteriana (Gil, Loscos \& Illueca, 2004, p. 309). Está formado largamente a través de la mineralización de la placa dental, por las sales de calcio, en las secreciones salivales y subgingivales (Mickleburgh, 2012). Es un factor de riesgo de las enfermedades periodontales, ya que interviene en la progresión de estas, al ser el principal depósito de placa bacteriana y dificultar su eliminación debido a su superficie rugosa.

La presencia de cálculo dental tiene como mayor factor de formación una escasa o inexistente higiene bucal, así mismo, la acumulación del cálculo dental está íntimamente ligado al hábito alimenticio de una población, teniendo en cuenta que al mantener un tipo de pH salival (escala de acidez y alcalinidad en la cavidad bucal) alcalino constante en la cavidad bucal, está asociado a un consumo alto de proteínas (Lieverse, 1999). 


\subsection{Enfermedad Periodontal}

La enfermedad periodontal se define como un conjunto de patologías localizadas en la encía y las estructuras de soporte de la pieza dental (encía, ligamento periodontal, cemento y hueso alveolar), se produce por bacterias que provienen de la placa bacteriana. Estas bacterias juegan un rol importante en el desarrollo de la periodontitis, que comienza con la formación de una bolsa periodontal, posterior destrucción del tejido conectivo y reabsorción del hueso alveolar a través de un mecanismo inmunopatogénico (Bascones y Figuero, 2005, p. 147).

La enfermedad periodontal, se ha clasificado en Gingivitis, que se desarrolla en la parte superficial de la encía y, por otro lado Periodontitis, término que refiere a una infección aguda que actúa sobre los tejidos conectivos de la pieza dental, en la que provocan reacciones inflamatorias e inmunológicas, es decir conforman un cúmulo de células asociadas a la activación de procesos de destrucción periodontal, llegando a deshacer la inserción del tejido que conecta al cemento, formando bolsas periodontales, reabsorbiendo el hueso alveolar que se ubica en los tejidos más profundos, movilizando el diente y finalizando con su caída (Bascones y Figuero, 2005).

\subsection{Lesiones pulpoalveolares}

Las lesiones pulpoalveolares son patologías infecciosas, que son influenciadas por las características patogénicas, por el número de microorganismos agresores que invaden a través de aberturas no naturales, en conjunción con la dinámica de la respuesta del huésped. Esta interacción entre los mi-

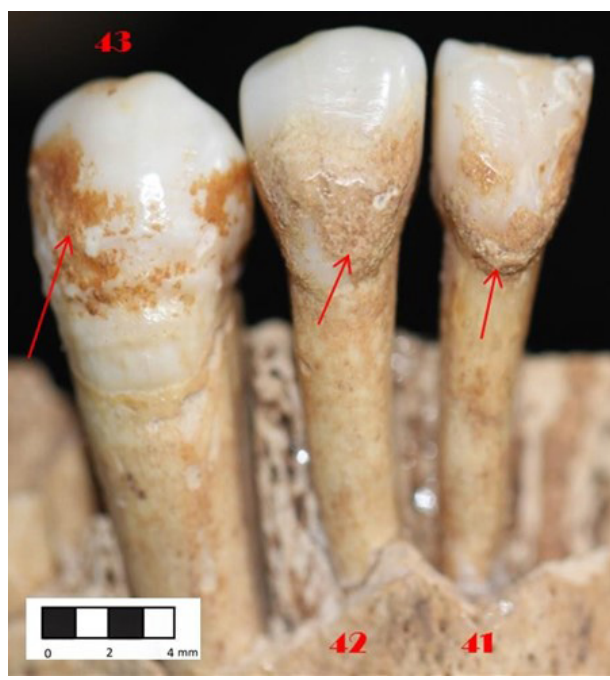

Figura 5. Individuo 7, presenta acumulación de cálculo dental en las superficies vestibulares de los incisivos central (41) y lateral (42). El canino presenta pigmentación marrón debido a porosidad dentaria.

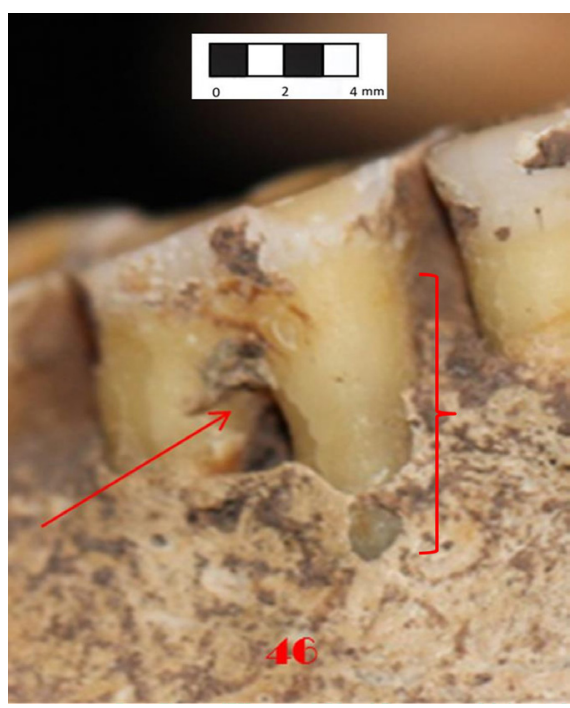

Figura 6. Individuo 17, el segundo molar inferior (46) presenta reabsorción alveolar (enfermedad periodontal) causado por acumulación de cálculo dental por encima del margen de la encía, provocando que los tejidos de soporte del diente, hueso alveolar, se retraigan dejando descubierto el fulcron (espacio de unión de las raíces) y las raíces del molar. 
croorganismos y la respuesta del huésped determinan los diferentes tipos de alteraciones pulpoalveolares (Sapp, et al. 1998, p.74).

\subsubsection{Abscesos}

Un absceso dental es la acumulación de pus; causada por una infección bacteriana, puede ocurrir en diferentes regiones del diente por diferentes razones, puede ser de dos tipos: Absceso Periodontal, que es una infección purulenta localizadas

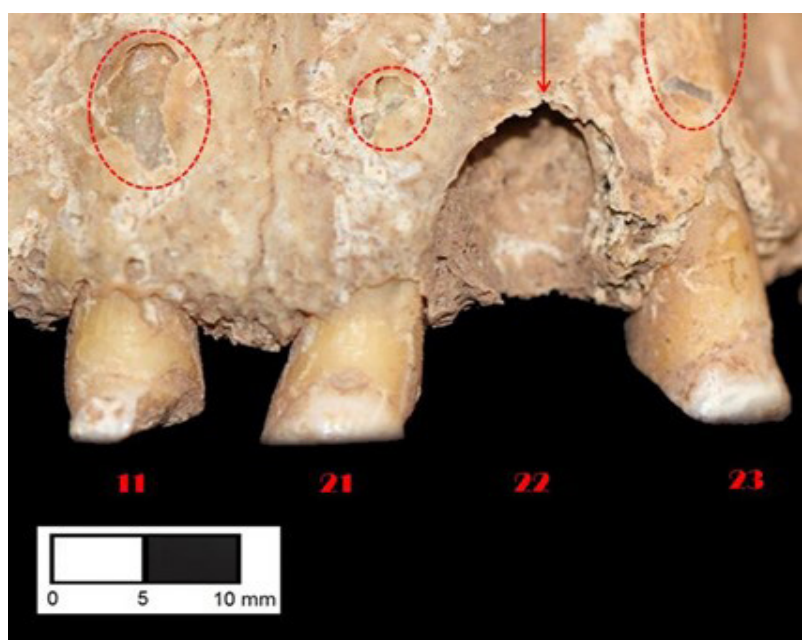

Figura 7. El incisivo lateral izquierdo (22), evidencia que tuvo un absceso periodontal, con pérdida de incisivo, el absceso destruyo el hueso alveolar y parte de la tabla ósea externa maxilar. El canino (23) presenta dehiscencia.

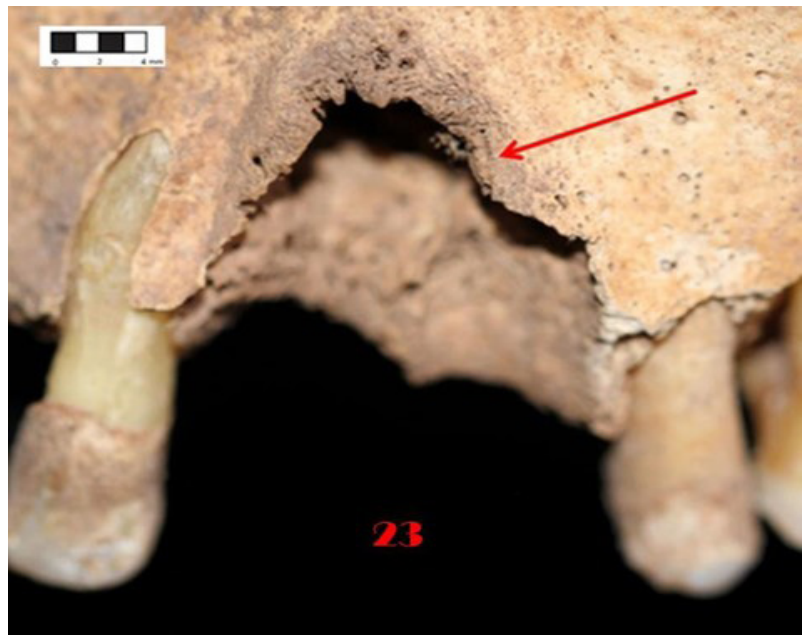
en los tejidos periodontales, se produce por medio de una bolsa periodontal preexistente que permite la acumulación de bacterias debajo de la encía provocando una infección purulenta que destruye el ligamento periodontal y el hueso alveolar (figura 7).

Otro tipo es el Absceso Periapical, que es una inflamación aguda caracterizada por una acumulación de material purulento localizada en el ápice de una pieza dental.(Mosby, 2009).Sucede cuando se tienen expuestas las superficies del esmalte dental, permitiendo que las bacterias infecten la cavidad pulpar llegando a necrosarse (figura 8 y 9).

Figura 8. Individuo 16 Canino (23) presenta absceso periodontal, proceso infeccioso crónico, nótese la coloración oscura del hueso alveolar, que provocó la destrucción de los tejidos del soporte del diente, finalizando con movilidad dental y posterior pérdida del diente 


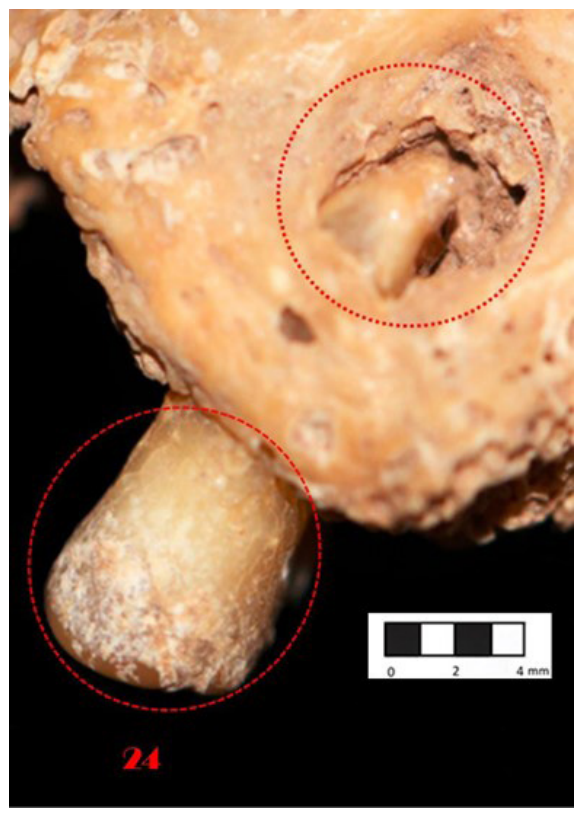

Figura 9. Individuo 04, Primer premolar (24) presenta absceso periapical con destrucción del hueso alveolar (fístula) y exposición del tercio apical de la raíz, producido por desgaste severo con pérdida total de corona.

\subsection{Desgaste dental}

El desgaste dental está definido como la contínua pérdida de esmalte dental y posterior compromiso de la dentina y puede llegar inclusive a la cavidad pulpar. Se conoce que el esmalte dental se desgasta con el paso de los años. Sin embargo, es relevante conocer cómo se produce dicho desgaste y si éste es una cuestión de carácter fisiológico o se trata de una manifestación patológica (Hillson 1996, p. 231).

El desgaste fisiológico, es parte normal del proceso de envejecimiento, sin embargo, cuando la pérdida del tejido dental es excesiva como en el bruxismo, la atrición empieza a ser patológica (Mosby, 2009, p. 66).

En época pre Inca e Inca es común observar diferentes tipos de desgaste dental, especialmente en piezas dentales molares y premolares. Valdivia(1988). Los factores influyentes son varios, entre ellos: el tipo de procesamiento de los alimentos; durante el proceso de molienda de los granos en batanes de piedra, se desprenden pequeñas partículas con alto componente silíceo, los que al ser al ser consumidos generan un fuerte desgaste de la superficie oclusal llegando a destruir las cúspides de los dientes (Krenzer, 2006, p. 8).

Asimismo, es probable que la textura de los alimentos (duros y fibrosos) los que, al ser consumidos, hayan contribuido al desgaste dental. Por otro lado, los factores culturales como el uso de los dientes como tercera mano, utilizados para preparar materiales, sostener objetos, como por ejemplo en la elaboración de los textiles, o también pudieron utilizar los dientes como alicates, etc. 
Por otro lado, el desgaste dental está relacionado con el consumo de hojas de coca, debido a ello, en 1998, Etty Indriati llevó a cabo una amplia investigación de personas modernas que consumen coca en los andes de Perú, Bolivia y Chile, realizando una entrevista acerca de sus consumos de hojas de coca. Como resultado de sus exámenes y entrevistas, ella concluyó que el indicador más fuerte de consumo de hojas coca es la alta presencia de caries en la parte cervical de la raíz en piezas dentales mandibulares acompañados de exposición de raíz, así mismo identifica pérdida post mortem de molares, caries en premolares, caries interproximal (Indriati 1998; Indriati \& Buikstra, 2001). El consumo de coca viene acompañado con un componente alcalino, ceniza alcalina, llamada "llipta" o con otros nombres "Ishku" o "Tocra", es una pasta

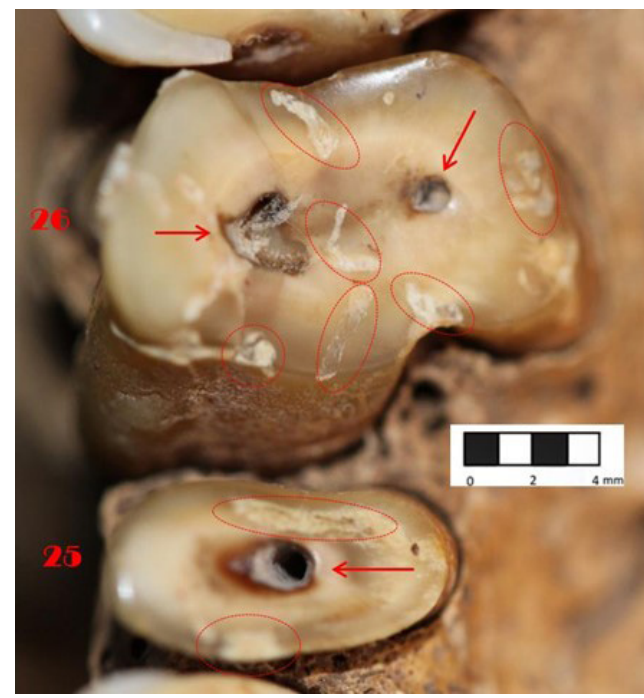

Figura 10. Individuo 01, segundo premolar (25) y Primer molar (26) ambos dientes con desgaste total de corona con exposición de los canales radiculares, necrosis pulpar y con presencia de manchas blancas producida por descalcificación.

formada de las cenizas de varias plantas, entre ellas: Quinua, markju, quishuar, y otros; los que posteriormente son disecadas y mezcladas con minerales como la sal, salitre, ccollpa, etc. Finalmente se obtiene una pasta sólida, en forma de barras o cubos (Dávila, 1993).

Esta pasta está caracterizada por ser una sustancia alcalina, causa variación del ph salival que puede producir desgaste químico denominado erosión en las superficies oclusales de los dientes (Goicochea, 1954; Coronel, 1988; Langsjoen 1996; Van Dalen, 2015) (figuras 10 y 11).

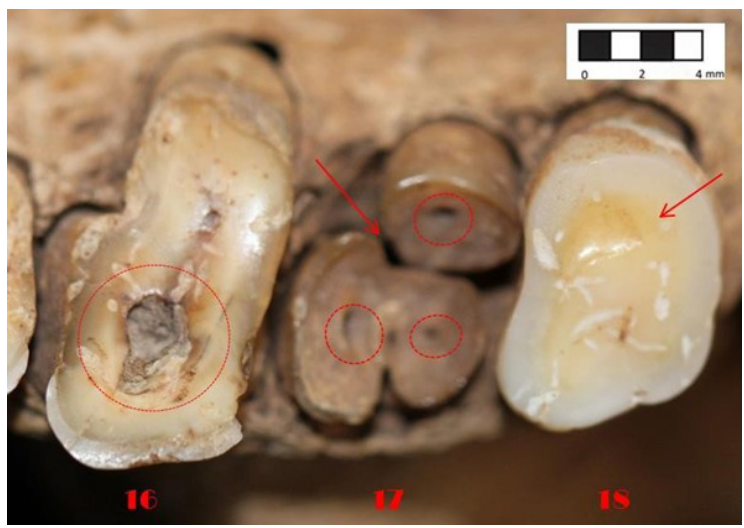

Figura 11. Individuo 01, primer molar derecho (16) presenta desgaste excesivo de corona con exposición de la cámara pulpar de forma oblicua. El segundo molar derecho (17) presenta desgaste con pérdida total de corona, desgaste radicular con pérdida de fulcron y con exposición de los canales radiculares. Y el tercer molar derecho (18) presenta desgaste con exposición de dentina. 


\section{MATERIAL Y MÉTODO}

Se realizó un análisis paleopatológico dental detallado de una colección osteológica humana de 17 individuos, con al menos una pieza dentaria y/o un maxilar y en buen estado de conservación, pertenecientes al Período Formativo de la región Cusco, cronológicamente se ubica entre los 400-100 a. C., pertenecientes al Proyecto de Investigación Arqueológica de Yuthu, Distrito de Maras, Provincia de Urubamba - Cusco, realizados por los arqueólogos Allison R. Davis y Carlos Delgado Gonzales entre los años 2005 y 2009.

Tabla 1. Cantidad de individuos, edad y sexo.

\begin{tabular}{|c|c|c|}
\hline $\mathbf{N}^{\circ}$ de individuo & Edad & Sexo \\
\hline 1 & Entre 26 a 35 años & Masculino \\
\hline 2 & Entre 11 a 12 años & Indeterminado \\
\hline 3 & Entre 18 a 28 años & Masculino \\
\hline 4 & Mayor de 46 años & Femenino \\
\hline 5 & Entre 1 a 2 años & Indeterminado \\
\hline 6 & Entre 11 a 12 años & Indeterminado \\
\hline 7 & Entre 15 años a 16 años & Indeterminado \\
\hline 8 & Entre 26 a 35 años & Femenino \\
\hline 9 & Entre 5 a 6 años & Indeterminado \\
\hline 10 & Entre 1 a 2 años & Indeterminado \\
\hline 11 & Entre 16 a 17 años & Femenino \\
\hline 12 & Entre 1 a 2 años & Indeterminado \\
\hline 13 & Entre 7 a 8 años & Indeterminado \\
\hline 14 & Entre 26 a 45 años & Femenino \\
\hline 15 & Entre 36 a 45 años & Femenino \\
\hline 16 & Entre 46 a 35 años & Femenino \\
\hline 17 & Entre 26 a 35 años & Masculino \\
\hline
\end{tabular}

Nota. Valerie Andrushko de la Universidad del Estado Sur de Connecticut llevó a cabo los análisis de: determinación de edad y sexo e identificación de traumas de los individuos de los entierros de Yuthu. 
En el estudio de las paleopatologías dentales se desarrollaron tres niveles de análisis: macroscópico-morfológico, radiológico e histológico, en este estudio se utilizó la técnica macroscópica-morfológica, es decir la observación directa de la patología y el radiológico (Ricalde y Nuñez, 2017).

Posteriormente se utilizaron los instrumentos de recolección de datos y códigos para las paleopatologías identificadas, según el protocolo de valoración de parámetros en paleoodontología, propuestas por Kutsner (2003), para el registro se hizo uso del odontograma y norma del odontograma, adaptadas para cada dentición decidua o permanente, según el formato utilizado por la federación dental internacional (FDI) y recomendada por la Organización mundial de Salud (OMS), donde se localizó y registró las diferentes patologías dentales que exhibió cada individuo, permitiendo la obtención de datos personalizados por cada individuo de la muestra. Finalmente se procesaron los datos estadísticamente para dar paso a los resultados de la investigación.

\section{RESULTADOS PALEOPATOLOGÍAS DENTALES}

Las frecuencias de las paleopatologías dentales que afectaron a los individuos de la población prehispánica de Yuthu, de acuerdo a los análisis estadísticos fueron:

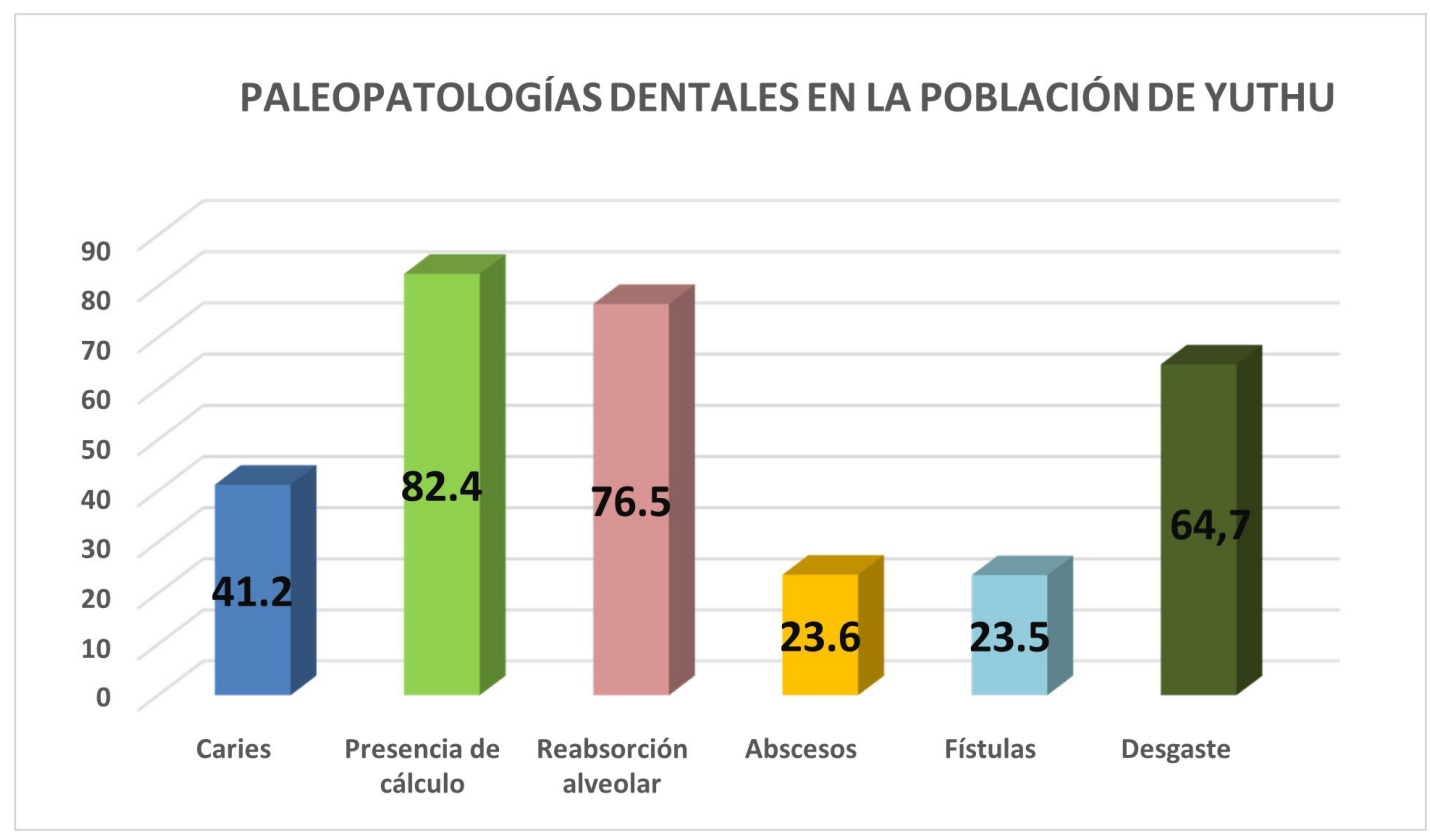

Figura 12. Histograma de las frecuencias de Paleopatologías dentales en la población de Yuthu. 
1. Caries dental, la presencia de caries tiene una frecuencia de $41.2 \%$, se caracteriza por presentar lesiones superficiales sin exceder el espesor del esmalte, esto nos muestra que se tuvo una dieta no cariogénica. El frecuente consumo de alimentos abrasivos cuya textura era dura y fibrosa, y al ejercer una mayor fuerza y tiempo de masticación contribuyó a una limpieza natural de los dientes, esto se corrobora con la ausencia de caries en las superficies interproximales de las piezas dentales lo que confirmaría el consumo de alimentos poco refinados y de naturaleza abrasiva. Así mismo, el desgaste excesivo de las piezas dentales en individuos adultos, ocasionaron que las lesiones cariosas, si es que estuvieron presentes, desaparecieran.

2. El cálculo dental es la patología dental con mayor frecuencia y que caracteriza a esta población, representado por $82.4 \%$. La etiología de la presencia de cálculo dental, está directamente ligado a una inexistente higiene bucal, así como un hábito alimenticio cuyo contenido es un consumo alto de proteínas de origen vegetal como la Quinua y de origen animal, como los camélidos los que provocaron un ph salival altamente alcalino constante en la cavidad bucal, que favoreció la mayor precipitación de sales de la saliva provocando la mineralización de la placa dental, posteriormente dando como resultado la acumulación de cálculo dental.

3. Enfermedad periodontal (reabsorción alveolar), posee una frecuencia de $76.5 \%$, se caracteriza por la presencia de Gingivitis, que consiste en depósitos de cálculo dental en la parte superficial de las encías llegando a causar la disminución de los tejidos de soporte de la pieza dental como: encías, ligamento periodontal, hueso alveolar, que en su grado más avanzado produce la reducción de volumen y tamaño de la porción residual alveolar de la mandíbula o maxilar finalizando con la movilidad del diente y pérdida ante mortem de la pieza dental.

4. Lesiones pulpoalveolares Lesiones en la tabla ósea externa maxilar y mandibular, se identificaron dos tipos:

4.1. Absceso periapical, con una frecuencia de $23.5 \%$, se caracteriza por presentar fístulas que se define como la perforación de la tabla ósea externa provocada por la aparición de una vía de salida de material purulento. Esta patología está estrechamente vinculada al desgaste dental excesivo, que llegó a provocar la exposición la cámara pulpar terminando en una infección y necrosis.

4.2. Abscesos periodontales, presenta una frecuencia de $23.6 \%$ cuya etiología comienza con la aparición de depósitos de cálculo subgingival, es decir ubicados por debajo del margen de la encía, lo que finalmente provoca la pérdida de la pieza dental por la infección y destrucción de los tejidos periodontales

5. Desgaste dental, posee frecuencia de $64.7 \%$, la etiología de esta paleopatología es diversa, sin embargo, entre las más influyentes causas tenemos: la forma de procesamiento de los alimentos, la utilización de moliendas de piedra, dado que los 
granos al ser molidos en batanes de piedra desprenden pequeñas partículas, que poseen un alto componente silíceo, durante el proceso de molienda, los que posteriormente al ser consumidos generan un mayor desgaste dental en la superficie oclusal, llegando a destruir las cúspides de los dientes. Por otro lado, otro factor influyente es el constante consumo de alimentos abrasivos de textura dura y fibrosa.

Así mismo, aparte de la dieta hay factores culturales que causan desgaste dental, como el uso de los dientes como tercera mano, entre estas actividades: preparar materiales, ablandar o limpiar pieles o sostener objetos mientras se pesca, caza o trabaja. Sin embargo, estos factores no son suficientes para justificar el excesivo desgaste dental que poseen los pobladores de Yuthu, dado que es imposible que se haya llegado a tal desgaste únicamente por los hábitos alimenticios, porque durante el proceso de masticación las superficies oclusales no entran en contacto directo, para llegar a tal grado, que presentan un desgaste total de corona dental y exposición de la cámara pulpar; por lo que se plantea la presencia de desgaste dental de tipo patológico como el bruxismo (Ricalde y Nuñez, 2017).

De acuerdo con los análisis, las condiciones de salud bucal de los individuos de Yuthu, fueron precarias debido a la inexistencia de prácticas de higiene bucal lo que favoreció a la presencia de paleopatologías dentales de carácter infeccioso (caries, cálculo dental, enfermedad periodontal y lesiones pulpoalveolares). Estas paleopatologías provocaron que los pobladores de Yuthu padecieran de dolores a nivel de las encías, dientes, además de sensibilidad dental, sinusitis, dolores de cabeza, halitosis, dolor muscular todo ello provocando una deficiente masticación.

En lo referente a la dieta los individuos de Yuthu tuvieron una alimentación que contenía un consumo elevado de proteínas de origen animal (Lieverse, 1999, p.219), como carne de camélidos, venado, pato, cuy, etc., complementada con el consumo de carbohidratos de tipo mono y disacáridos (glucosa y fructuosa), presente en las frutas, verduras o del tipo polisacáridos (almidón y celulosa) presentes en los cereales, tubérculos, legumbres y verduras como la quinua, kiwicha, frejoles, oca, maíz y papa, los que poseía un potencial cariogénico bajo.

Agradecimientos: Sinceros agradecimientos al magíster en Arqueología Alfredo Candía Gómez, por su asesoramiento, haber dedicado su valioso tiempo y esfuerzo en la realización y conclusión del presente trabajo de investigación. Del mismo modo agradecimiento al Lic. en Arqueología Carlos Mauricio Delgado Gonzales, por facilitarnos el material óseo del Proyecto de Investigación Arqueológica de Yuthu.

De igual manera a: odontólogo Marco Antonio Farfán Ochoa, por su importante colaboración brindada en la realización del análisis de las muestras, a la antropóloga Elba Torres Pino, por su asesoramiento en el área de Antropología física, a la odontóloga Yahaira Soledad Ricalde Pino, por su apoyo en la elaboración y desarrollo la presente investigación. 


\section{REFERENCIAS BIBLIOGRÁFICAS}

Altamirano Enciso, A. (2013). Observaciones paleopatológicas a la tesis de bachiller de Julio C. Tello. Arqueología y Sociedad, (26), 71-90.

Andrushko, V. A. (2008). Yuthu Complete Burial Summaries. Informe inédito.

Aufderheide, A.C. (2000). Progress in soft tissue paleopathology. JAMA. 284(20), 2571-3.

Bethard, J. D., Gaither, C., Vásquez, V.F., Tham, T.R.y Kent, J.D. (2008). Isótopos Esta-

bles, dieta y movilidad de los pobladores de un conjunto residencial en Santa Rita B, Valle de Chao, Peru Revista de Bioarqueología ARCHAEOBIOS, (2),19-27.

Bonnet, G. P. (2001). Informe de investigación arqueológica en el Parque Arqueológico de Saqsayhuman, sector Muyogmarka (muro perimétrico). Instituto Nacional de Cultura, Dirección de Investigación y Catastro, INC: Cusco.

Brier, Bob. (1994). Paleopathology: the dead are our teachers. En: B. Brier (Ed.). Egyptian Mummies Unraveling the Secrets of fan Ancient Art (pp. 174-93) New York: William Morrow.

Covey A. R. y Yepez, W. (2004). Informe preliminar Proyecto de Reconocimiento Intensivo Xaquixaguana (PRIX). Reconocimiento sistemático de la Región Maras-Chinchero -Temporada I. Instituto Nacional de Cultura INC: Cusco.

Coronel, A. (1988). Estudio comparativo de la prevalencia de caries, enfermedad periodontal y abrasión entre un grupo de sujetos con el hábito de masticación de hojas de coca y un grupo control de la comunidad de Apaycanchilla, provincia de Tarma. Tesis para optar título de licenciatura, E. P. de Estomatología. Universidad Peruana Cayetano Heredia. Lima.

Davis, A. y Delgado, C.M. (2009).Investigaciones Arqueológicas en Yuthu: Nuevo datos sobre el Periodo Formativo en el Cusco, Perú (400-100 a. C.) Boletín de Arqueología PUCP, (13), 347-372.

Dávila, L. (1994). Q'eros herencia Inca: Testimonio de expediciones odontológicas. Cusco.

Davis, A. (2011). Yuthu Community and Ritual in an Early Andean Village. Ann Arbor Michigan, Unites States of America: University of Michigan.

Gil, R., Loscos, F. y Illueca, F. (2004). Cálculo dental y control químico de su formación. Periodoncia y Osteointegración, 14(4), 309-321.

Goicochea, A. (1954). Estudio de la cavidad bucal en los sujetos habituados a la masticación de hojas de coca en la hacienda Collambay -Trujillo. Tesis para optar el título de Odontólogo, E.P. de Estomatología, Facultad de Ciencias de la Salud, Universidad Nacional Mayor de San Marcos. Lima.

Hillson, S. (1996). Dental Anthropology. Cambridge: Cambridge University Press. 
Indriati, E. (1998). A dental Anthropological Approach to Coca-Leaf Chewing in the Andes. Ph.D, dissertation, University of Chicago.

Indriati, E. \& Buikstra, J. (2001). Coca Chewing in Prehistoric Coastal Peru: Dental Evidence. American Journal of Physical Anthropology, (114), 242-257.

Krenzer, U. (2005). Antropología Dental. Compendio de métodos antropológico forenses para la reconstrucción del perfil osteobiológico 6. Guatemala: CAFCA.

Küstner, E. (2003). Perspectiva odontoestomatológica en paleopatología. En E. Küstner (Ed.), Paleopatología la enfermedad no escrita (pp. 151-161). Barcelona: MASSON.

Langsjoen, O. M. (1996). Dental effects of diet and coca-leaf chewing on two prehistoric cultures of northern Chile. American journal of physical Anthropology, 101(4), 475-89.

Lieverse, A.R. (2009). Diet and Aetiology of Dental Calculus. International Journal of Osteoarchaeology 9(4), 209-232.

Larsen, C. (2002). Bare Bones Anthropology: The biarchaeology of human remains. En P. Peregrine, C. Ember y M. Ember (Eds.), Archaeology: Original reading in method and practice (pp. 111-128). New Jersey: Prentice Hall. Mosby. (2009). Diccionario de odontología. España: Elsevier.

Mejía, A. M., Lomelí, G. y Gaxiola, M. C. (2012). Manual de procedimientos estandarizados para la vigilancia epidemiológica de las Patologías Bucales. Dirección General de Epidemiología DGE. México: Dirección General de Epidemiología.

Mickleburgh, H. L. (2012). Unusual Patterns of Dental calculus deposits in skeletal Material from the Site of Manzanilla, Trinidad: Bioarchaeological Evidence for Habitual Coca Leaf Chewing? Caribbean Connections (pp. 1 -13).

Pezo, L. N. (2010). Modo de vida y expectativas de salud de comunidades del litoral de la costa norte del Perú durante el periodo formativo. Universidad Nacional Mayor de San Marcos, Lima, Perú.

Previgliano, C., Ceruti, C, Arias, F, Gonzales, J y Reinhard, Johan. (2005). Radiología en estudios arqueológicos de momias Incas. Revista Argentina de radiología, 69(3), 199-210.

Ricalde, A. S. y Nuñez, G. (2017). Análisis Paleopatológico Dental de la población prehispánica del Sitio Arqueológico de Yuthu (Período Formativo), Distrito de Maras, Provincia de Urubamba - Cusco (400 - 100 a. C). Tesis para optar el título profesional de Licenciado en Arqueología. Escuela profesional de Arqueología, Facultad de Ciencias Sociales, Universidad Nacional de San Antonio Abad del Cusco. 
Rodríguez, C. D. (2005). La antropología dental y su importancia en el estudio de los grupos humanos. Revista Facultad de Odontología Universidad de Antioquia, 16(1 y 2), 52-59.

Sapp, J. P., Eversole, R. L. \& Wysocki, P. G. (1998). Patología oral y maxillofacial contemporánea. España: Harcourt Brace.

Torres, E. (2003). Contextos funerarios. Instituto Nacional de Cultura INC: Cusco.

Tomasto, E. L. (2009). Caries dental y dieta en poblaciones prehispánicas de los valles de Palpa, costa sur del Perú (3500 a. C - 1000 d. C). Pontificia Universidad Católica del Perú, Lima, Perú.

Van Dalen, P., Grados, H., Medina, F. y Malpartida, M. (2015). Conviviendo con los ancestros: Investigaciones Arqueológicas en Rupac, Huaral. Arqueología y Sociedad, (30), 425-472.

Vásquez, V. y Rosales Tham, T. (2009). Análisis de restos de fauna y vegetales del sitio Yuthu. Informe del Centro de Investigaciones Arqueobiológicas y Paleoecológicas Andinas ARQUEOBIOS. Trujillo.

Valdivia, L. (1988). Odonto antropología peruana. Lima: Ministerio de la Presidencia. Consejo Nacional de Ciencia y Tecnología CONCYTEC.

Verano, J. W. (1997). Advances in paleopathology of Andean South America. Journal of World Prehistory.11(2), $237-68$.

\section{SOBRE LA AUTORA}

\section{Angela Silvia Ricalde Pino}

Licenciada en arqueología por la Universidad Nacional de San Antonio Abad del Cusco. Diplomado en Peritaje Antropología Social y Físico Forense. Expositora de diversos eventos, coloquios nacionales e internacionales en temas de Bioarqueología (ALAF, ENAH). Actualmente dirige proyectos de Intervención Arqueológica en el Distrito de Pachacamac, región de Lima. 